\title{
Mortality in Patients with Brainstem Cavernous Malformations
}

\author{
Julia Velz ${ }^{a, b}$ Marian Christoph Neidert ${ }^{a, b, c}$ Yang Yanga, b, c Kevin Akeret $^{\text {a, b }}$ \\ Peter Nakaji $^{d} \quad$ Luca Reglia,b Oliver Bozinova,b, c \\ aDepartment of Neurosurgery, Clinical Neuroscience Center, University Hospital Zurich, Zurich, Switzerland; \\ bUniversity of Zurich, Zurich, Switzerland; 'Department of Neurosurgery, Kantonsspital St. Gallen, St. Gallen, \\ Switzerland; dDepartment of Neurosurgery at Banner, University Medical Center Phoenix, Phoenix, AZ, USA
}

\section{Keywords}

Brainstem cavernous malformations - Natural course .

Surgery $\cdot$ Mortality $\cdot$ Causes of death

\begin{abstract}
Objective: Brainstem cavernous malformations (BSCM)-associated mortality has been reported up to $20 \%$ in patients managed conservatively, whereas postoperative mortality rates range from 0 to $1.9 \%$. Our aim was to analyze the actual risk and causes of BSCM-associated mortality in patients managed conservatively and surgically based on our own patient cohort and a systematic literature review. Methods: Observational, retrospective single-center study encompassing all patients with BSCM that presented to our institution between 2006 and 2018. In addition, a systematic review was performed on all studies encompassing patients with BSCM managed conservatively and surgically. Results: Of 118 patients, 54 were treated conservatively ( 961.0 person years follow-up in total). No BSCM-associated mortality was observed in our conservatively as well as surgically managed patient cohort. Our systematic literature review and analysis revealed an overall BSCM-associated mortality rate of $2.3 \%$ (95\% Cl: 1.6-3.3) in 22 studies comprising 1,251 pa-
\end{abstract}

karger@karger.com www.karger.com/ced

Karger $\stackrel{\text { ' }}{5}$

GOPEN ACCESS
C 2021 The Author(s).

Published by S. Karger AG, Basel

This article is licensed under the Creative Commons Attribution 4.0 International License (CC BY) (http://www.karger.com/Services/ OpenAccessLicense). Usage, derivative works and distribution are permitted provided that proper credit is given to the author and the original publisher. tients managed conservatively and of $1.3 \%$ (95\% Cl: 0.9-1.7) in 99 studies comprising 3,275 patients with BSCM treated surgically. Conclusion: The BSCM-associated mortality rate in patients managed conservatively is almost as low as in patients treated surgically and much lower than in frequently cited reports, most probably due to the good selection nowadays in regard to surgery.

(C) 2021 The Author(s).

Published by S. Karger AG, Basel

\section{Introduction}

Brainstem cavernous malformations (BSCM) are lowflow vascular lesions that can result in significant neurological morbidity [1]. Mortality rates following surgery range from 0 to $1.9 \%$ in the literature, whereas mortality rates of up to $20 \%$ have been reported for patients managed conservatively $[1,2]$.While the 1st BSCM hemorrhage is often benign, repeat BSCM hemorrhages, which have been reported in up to $60 \%$ of patients, often create a progressive pattern of neurological decline, with most patients never returning to their pre-hemorrhage baseline [3-5]. Risk assessment with regard to morbidity and
Correspondence to:

Julia Velz, julia.velz@usz.ch 
mortality is therefore essential to balance the risk of surgery against the natural history of BSCM. An accumulating volume of the literature detailing their surgical management has demonstrated high cure rates and low rates of postoperative morbidity in carefully selected groups of patients [3, 6-9]. Whereas early postoperative morbidity is high, ranging from 29 to $67 \%$ in larger surgical series (although often transient), a relatively low surgery-related mortality rate of up to $1.9 \%$ is currently described in the literature [2,9-11]. In contrast, the natural history of BSCM remains poorly understood given the paucity of data and there remains disagreement and uncertainty about the BSCM-associated mortality risk in patients with BSCM managed conservatively. Most studies which analyzed the natural course of BSCM focused on the (re-) hemorrhage rate and BSCM-associated morbidity, whereas BSCM-associated mortality in patients followed conservatively remains reluctantly reported and discussed. A BSCM-associated mortality rate of up to $20 \%$ was reported in 1994 for patients managed conservatively and is still frequently cited, which seems nowadays extensively high compared to the mortality rates described in surgically treated patients $[1,2,5,9,12]$. The goal of this study was to systematically analyze the actual risk and causes of BSCM-associated mortality in patients managed conservatively and surgically based on our own patient cohort and a systematic review of the literature.

\section{Methods}

\section{Study Population}

We performed a retrospective single-center study, encompassing all patients with BSCM that presented to our institution, the Department of Neurosurgery of the University Hospital Zurich, a tertiary reference center, between 2006 and 2018. Patients fulfilling the following criteria were eligible and included: (1) radiological or histological diagnosis of BSCM and (2) available follow-up (FU) data. Radiological and histological diagnoses of BSCM were confirmed either by a senior neuroradiologist and/or neuropathologist. The electronic patient chart was screened for patient baseline characteristics, causes and occurrence of death, information regarding the FU (still ongoing, has been completed, or the patient is lost to FU), and modified Rankin Scale at final FU to determine the degree of disability.

\section{Patient Management}

We recommend conservative management to patients with none or single BCSM hemorrhage in absence of severe neurological deficits. In cases of recurrent BSCM hemorrhages or neurological decline surgical treatment is evaluated and discussed based on the lesion location (median, paramedian, and lateral lesion location) and possible safe entry zones $[13,14]$. We believe that not the depth of the lesion but more importantly a strictly midline or midline-crossing lesion is a limiting factor to surgical accessibility, as well as multiple BSCM [14].

We perform routine radiological and clinical FU 3 months after initial diagnosis of BSCM, and yearly in patients with BSCM managed conservatively. We have recently shown that routinely performed FU imaging in clinically stable patients with BSCM has no impact on surgical decision-making. Therefore, it appears reasonable to limit clinical management to patient education and symptom-driven FU strategy [15].

\section{Literature Search, Review, and Data Extraction}

A systematic literature review was performed on September 2020 in PubMed and Google Scholar using "cavernous malformation" or "cavernoma" or "cavernous angioma" and "brainstem." Studies with $\geq 2$ patients with BSCM, published between January 1986 and September 2020, and available information on the management (surgery vs. conservative management), as well as the neurological outcome at the final FU were eligible and included in the final analysis. Full text was obtained for all studies that were included in the final analysis. Extracted data of each study included the size of the patient cohort, performed treatment, causes and occurrence of death, and the average FU. BSCM-associated mortality was defined as any cause of death that is related to the BSCM, as well as any cause of death in patients treated surgically within 1 month after surgery. For articles with overlapping patient cohorts, the larger, more recent cohort was included in the final analysis.

Standard Protocol Approval, Registration, and Patient Consent The study was approved by the Cantonal Ethics Committee (KEKZH; Application number 2017-00330). No registered review protocol was used in this systematic review. This study follows Preferred Reporting Items for Systematic Reviews and Meta-Analyses guidelines.

\section{Statistical Analysis}

Continuous variables were expressed as means \pm standard deviation. Categorical variables were expressed as frequencies with percentages. The number of analyzed patients in each study as well as the number of BSCM-associated death was pooled for both groups (patients managed conservatively and surgically) and the proportions of BSCM-associated death and 95\% CIs were calculated. All analyses were performed using IBM SPSS Statistics version 25.0 (IBM Corp., Armonk, NY, USA).

\section{Results}

\section{Patient Demographic Data}

A total of 118 patients harboring BSCM fulfilled the abovementioned inclusion criteria and were included in the final analysis.

\section{Clinical Management}

A total of 118 patients were diagnosed with $\geq 1$ BSCM. Microsurgical resection of BSCM was performed in 64 patients $(54.2 \%)$, whereas 54 patients $(45.8 \%)$ were conservatively followed. The patients' baseline characteristics, as well as FU data, are summarized in Table 1. 
Table 1. Baseline patient characteristics

\begin{tabular}{|c|c|c|}
\hline Baseline patient characteristic & $\begin{array}{l}\text { Conservative manage- } \\
\text { ment - patients }(N=54)\end{array}$ & $\begin{array}{l}\text { Surgical treatment - } \\
\text { patients }(N=64)\end{array}$ \\
\hline Age in years at initial diagnosis, mean $\pm \mathrm{SD}$ (range) & $44.9 \pm 17.9(9.4-84.6)$ & $38.0 \pm 15.8(7.5-79.5)$ \\
\hline Years of FU, mean \pm SD (range), $n$ & $7.5 \pm 8.0(0.1-30.1)$ & $8.7 \pm 7.0(0.5-30.5)$ \\
\hline \multicolumn{3}{|l|}{ Sex, $n(\%)$} \\
\hline Male & $29(53.7)$ & $24(37.5)$ \\
\hline Female & $25(46.3)$ & $40(62.5)$ \\
\hline \multicolumn{3}{|l|}{ BSCM hemorrhage, $n(\%)$} \\
\hline No & $13(24.1)$ & 0 \\
\hline Yes & $41(75.9)$ & $64(100)$ \\
\hline \multicolumn{3}{|l|}{ BSCM location, ${ }^{*} n$} \\
\hline Mesencephalic & 18 & 10 \\
\hline Pontomesencephalic & 2 & 4 \\
\hline Pontine & 30 & 38 \\
\hline Pontomedullary & 7 & 8 \\
\hline Medullary & 6 & 6 \\
\hline \multicolumn{3}{|l|}{ Neurology, $n(\%)$} \\
\hline Asymptomatic & $17(31.5)$ & 0 \\
\hline Focal neurological deficits & $37(68.5)$ & $64(100)$ \\
\hline \multicolumn{3}{|l|}{ mRS at last FU, $n(\%)$} \\
\hline 0 & $21(38.9)$ & $2(3.1)$ \\
\hline 1 & $15(27.8)$ & $21(32.8)$ \\
\hline 2 & $9(16.7)$ & $22(34.4)$ \\
\hline 3 & $5(9.3)$ & $13(20.3)$ \\
\hline 4 & $3(5.6)$ & $5(7.8)$ \\
\hline 5 & $1(1.9)$ & $1(1.6)$ \\
\hline \multicolumn{3}{|l|}{$\mathrm{FU}, n(\%)$} \\
\hline FU ongoing & $37(68.5)$ & $42(65.6)$ \\
\hline FU completed & $8(14.8)$ & $9(14.1)$ \\
\hline Lost to FU & $6(11.1)$ & $9(14.1)$ \\
\hline Death & $3(5.6)$ & $4(6.3)$ \\
\hline \multicolumn{3}{|l|}{ Mortality, $n(\%)$} \\
\hline Mortality not associated to BSCM & $3(5.6)$ & $4(6.3)$ \\
\hline BSCM-associated mortality & 0 & 0 \\
\hline
\end{tabular}

BSCM, brainstem cavernous malformation; SD, standard deviation; FU, follow-up; mRS, modified Rankin Scale. * In patients with multiple BSCM, multiple brainstem locations are listed.

Surgical Treatment in Conservatively Managed

\section{Cohort}

In three instances, endoscopic 3rd ventriculostomy, and in one instance external ventricular drain placement, were performed after BSCM hemorrhage. In all 4 patients, BSCMs were located in the quadrigeminal plate and BSCM hemorrhage resulted in intraventricular bleeding with consecutive aqueduct stenosis and lifethreatening hydrocephalus.

\section{Mortality}

In the group of 54 patients managed conservatively, the overall mortality was $5.5 \%(n=3)$. None of the deaths was attributable to BSCM hemorrhage. One patient died after severe apoplexy, 1 patient died due to advanced tumor disease (myelodysplatic syndrome) and 1 patient died due to sequelae of severe neurodegenerative disease. In the group of 64 surgically treated patients, the overall mortality was $6.2 \%(n=4)$. None of the deaths was attributable to BSCM hemorrhage and/or surgery. Two patients died due to documented advanced tumor disease (lymphoma and breast cancer) and in 2 patients no data are available (1st: 11 years after complete resection of BSCM, 2nd: 9 months after BSCM surgery).

\section{Literature Review}

The literature search yielded 740 articles published between January 1986 and September 2020. After initial 


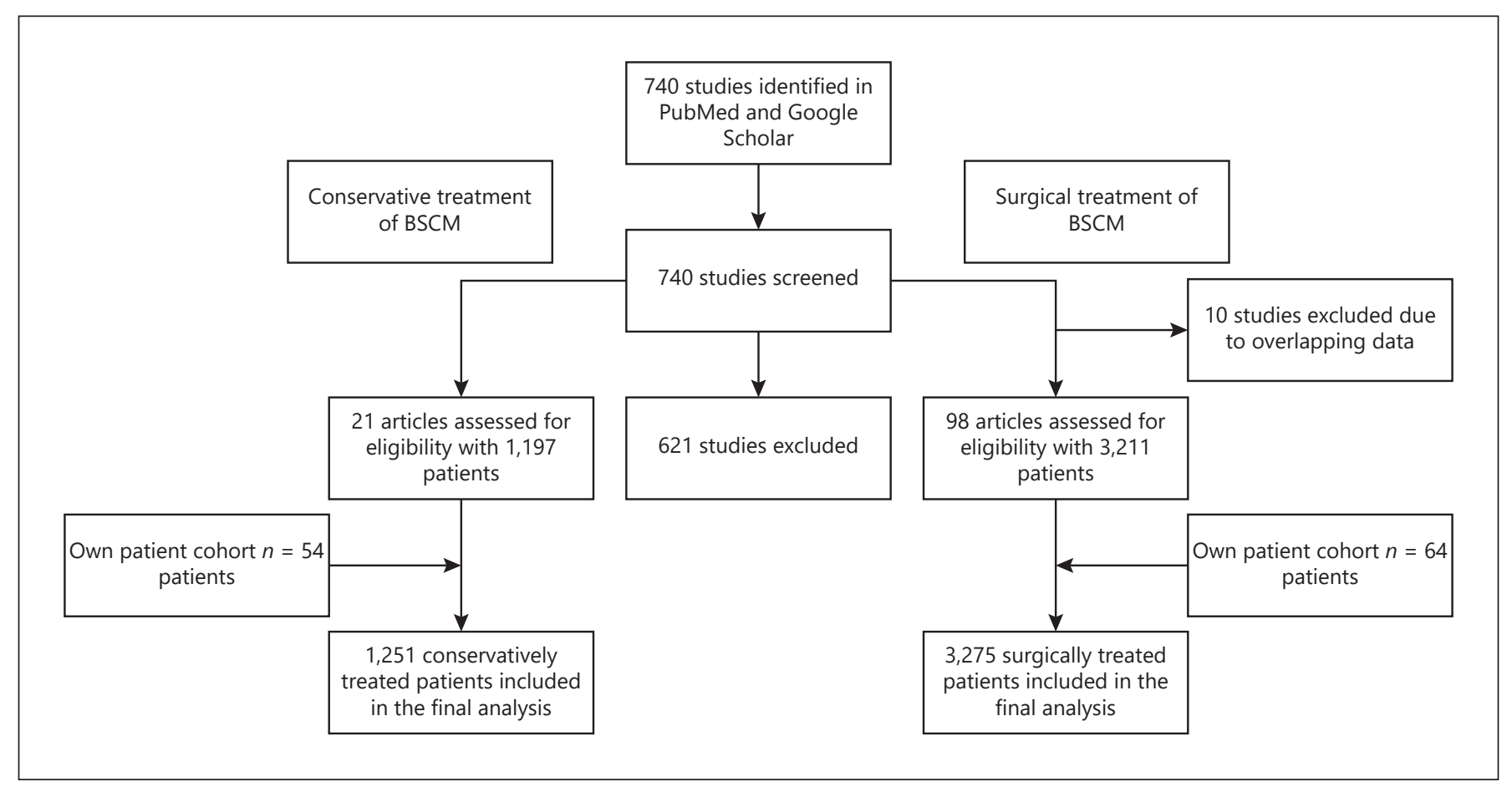

Fig. 1. Systematic review process.

screening and exclusion of studies with overlapping patients, 22 studies comprising 1,251 patients managed conservatively and 99 studies comprising 3,275 patients treated surgically were selected for analysis (Fig. 1 outlines the systematic review process, online suppl. Tables 1, 2; see www.karger.com/doi/10.1159/000516909 for all online suppl. material). BSCM-associated mortality occurred in $2.3 \%$ (95\% CI: $1.6-3.3 ; n=29 / 1,251)$ of patients with BSCM managed conservatively. In the majority, with 79.3\% $(n=23 / 29)$, the reason for BSCM-associated mortality was not further clarified, whereas recurrent hemorrhage was reported as causes of deaths in 4 patients $(13.7 \%)$, and tectal hemorrhage with hydrocephalus, as well as pneumonia caused due to progressive cranial nerve deficits, were reported in each 1 patient (each 3.5.\%) as causes of death (online suppl. Table 3) [1, 5, 16-21].

Mortality occurred in $1.3 \%$ (95\% CI: $0.9-1.7 ; n=$ $41 / 3,275$ ) of patients with BSCM treated surgically (online suppl. Tables 2,4). The most commonly reported cause of death was postoperative cranial nerve palsy with consecutive respiratory failure/pneumonia in 10 patients (24.4\%) [7, 10-12, 22-25]. In 7 patients (17.1\%), the causes of death were not further clarified; however, it was stated that the death was attributable to BSCM surgery $[16,19,26-30]$. Both cardiopulmonary arrest and re- bleeding of incomplete resected BSCM led to death in 3 patients (each 7.3\%) [5, 31-34]. BSCM hemorrhage, brainstem injury, cerebellar hemorrhage, and cerebellar infarction were reported as causes of death in each 2 patients (each $4.8 \%$ ) that had been treated surgically [7, 24, 31]. Further causes of BSCM-associated mortality in surgically treated patients described in the literature can be found in online suppl. Table 4.

\section{Discussion/Conclusion}

The natural history of untreated BSCM is not thoroughly documented and understood. To date, it is clear that asymptomatic patients who may very well never experience relevant hemorrhage from their lesion should not face the 29 to $67 \%$ risk of early morbidity and $15 \%$ risk of long-term worsening (under best care) after surgery [3, 5-7]. However, especially in patients in which microsurgical resection cannot be offered due to varying reasons (anatomical location, multiple BSCM, and overall condition of the patient), the question remains whether BSCM displays a life-threatening disease.

Previous studies regarding BSCM-associated mortality have been largely limited to patients managed surgi- 
Fig. 2. Mortality (\%) for each published study is plotted depending on the length of FU (months). Studies reporting surgical cases are depicted in green and conservatively managed cohorts are shown in red. The dot sizes represent the size of the cohort $(\mathrm{N})$. Studies without available information on the length of FU are not shown in this figure but are listed in online suppl. Tables 1, 2. FU, follow-up.

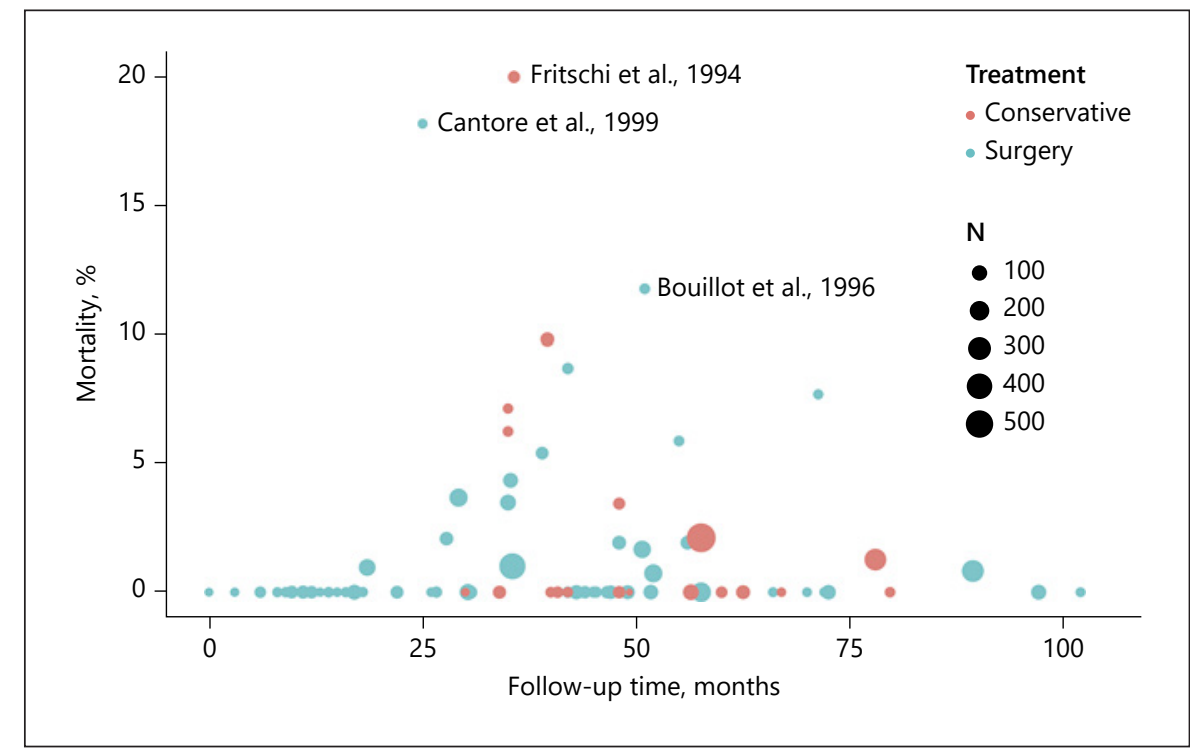

cally. Based on 86 studies comprising 2,493 patients, Kearns et al. [2] recently reported a BSCM-associated mortality rate in surgically treated patients of $1.6 \%$. However, BSCM-associated mortality in patients managed conservatively remains more reluctantly reported and discussed. A mortality rate of $20 \%$ was reported by Fritschi et al. [1] in 1994, whereas other studies with partly small case numbers have reported lower BSCM-associated mortality in BSCM managed conservatively [35].

It seems evident that the improvement in the surgical management of BSCM during the last decades led to a selection and publication bias regarding the risk and benefits of conservative versus surgical treatment. BSCMs with multiple hemorrhages or considered to be prone to bleed are more likely treated surgically. Yet, indication of surgical resection of BSCM varies among institutions: in cases of repeated hemorrhages associated with progressive neurological deficit, surgical resection of BSCM seems to be recommended by the vast majority of neurosurgeons $[3,5,6]$. Whereas the presence of that is, extralesional hemorrhage, mass effect of an exophytic lesion or a lesion abutting a surgically accessible pial membrane, as well as a rapidly expanding lesion are only considered by some neurosurgeons as a characteristic that makes it reasonable to intervene operatively [36]. Besides BSCM characteristics, BSCM location and surgical accessibility play a pivotal role in decision-making whether or not to intervene operatively in regard to benefit-risk assessment - however, surgical accessibility is differently evaluated and defined among institutions (i.e., based on the depth of the lesion, the two-point method, midline, or nonmidline crossing lesion) $[14,37]$. Given this selection and the consecutive publication bias, the question as to whether the natural course of BSCM is that of a lifethreatening disease will remain difficult to answer without an RCT randomizing patients to surgical versus conservative treatment, which for ethical concerns is very difficult to conduct. However, the aim of this study was to elaborate the mortality risk and causes of BSCM-associated mortality in patients with BSCM managed conservatively and surgically nowadays (taking into consideration that the assignment to conservative management vs. surgical treatment was in the majority of cases based on a neurosurgeons or neurologists recommendation), and we therefore performed a systemic literature review and analysis, encompassing all published studies with patients with BSCM managed conservatively or surgically.

In our conservative patient cohort, in which 54 patients did not undergo microsurgical resection of BSCM, intraventricular hemorrhage with aqueduct stenosis, and life-threatening hydrocephalus was the most common (and only) life-threatening risk factor. Due to endoscopic 3 rd ventriculostomy or external ventricular drain placement, none of the patients died. In all 4 patients, BSCMs were located in the quadrigeminal plate which identifies BSCM location in the mesencephalon as a potential risk factor for BSCM-associated life-threatening events in our patient cohort. Interestingly, BSCM hemorrhage in any other brainstem component (pontomesencephalic, pontine, pontomedullary, and medullary) did not led to a 
(potentially) life-threatening event. In the performed literature review, recurrent hemorrhage $(13.7 \%)$, tectal hemorrhage with consequent hydrocephalus (3.5\%), as well as BSCM hemorrhage with life-threatening cranial nerve deficits (3.5\%) were reported as reasons for BSCMassociated mortality in patients managed conservatively (online suppl. Table 3). Unfortunately, in the majority of cases $(79.3 \%)$, neither the reason for BSCM-associated mortality nor the affected brainstem location was described in detail. In total, considering 22 studies with 1,251 conservatively treated patients with BSCM, we elaborated a significantly lower BSCM-associated mortality rate with only $2.3 \%(n=29 / 1,251)$ in patients managed conservatively (online suppl. Table 1) compared to the previously reported and still frequently cited mortality rate of $20 \%$ [1]. The study by Fritschi et al. [1] with the stated BSCM-associated mortality of $20 \%$ in patients managed conservatively displays an outlier study nowadays, as shown in Figure 2.

Considering 99 studies with 3,275 surgically managed patients, we identified a mortality rate of $1.3 \%(n=$ $41 / 3,275$ ) (online suppl. Table 2), which is congruent with the currently reported mortality rate of up to $1.6 \%$ [2]. The most common reported cause of death in surgically treated patients, with $24.4 \%$, was postoperative cranial nerve palsy with consecutive respiratory failure/pneumonia (online suppl. Table 4) [7, 10-12, 22-25]. In 17.1\%, the causes of death were not further clarified; however, stated that the death was attributable to BSCM surgery $[16,19,26-30]$. Cardiopulmonary arrest and rebleeding of incompletely resected BSCM were reported in each 3 patients as causes of death [5, 31-34].

Limitations of our study are (I) the inherent limitations of retrospective and single-center cohorts; (II) the potential selection bias towards clinically more severe cases arising from the preselection of a tertiary care center; (III) the potential selection bias given the propensity to treat higher risk lesions (e.g., previous history of hemorrhage); (IV) a potential selection bias since patients with asymptomatic lesions (i.e., BSCM hemorrhage without neurological deficits) or a poor preoperative functional status might not have been brought to our attention; (V) the limitations of a literature review and incomplete patient information. Regarding this last point, given that there is a general bias against reporting poor results, it may be that the published rates of surgical morbidity may underrepresent the true surgical risks.

Risk assessment with regard to morbidity and mortality is the pivotal factor to balance the risk of surgery against the natural history of BSCM. Poor results in pa- tients treated surgically as well as managed conservatively should be reported to avoid false risk assessment. A prospective study with a large number of cases exploring in detail the morbidity and mortality in patients with BSCM managed surgically and conservatively is warranted and would add important information in regard to risk assessment to the current literature.

In summary, this literature review reveals that the once reported mortality rate of up to $20 \%$ in patients with BSCM managed conservatively is significantly lower nowadays. Given the present data, with an overall mortality rate of $2.3 \%$ in patients managed conservatively versus $1.3 \%$ in patients treated surgically with BSCM, patients should not feel more insecure in cases of conservative treatment recommendations.

\section{Statement of Ethics}

All procedures performed in studies involving human participants were in accordance with the ethical standards of the institutional and/or national Research Committee and with the $1964 \mathrm{Hel}-$ sinki declaration and its later amendments or comparable ethical standards. The study was approved by the Cantonal Ethics Committee (KEK-ZH; Application number 2017-00330). The written informed consent was obtained from all patients.

\section{Conflict of Interest Statement}

The authors have no conflicts of interest to declare.

\section{Funding Sources}

This research did not receive any specific grant from funding agencies in the public, commercial, or not-for-profit sector.

\section{Author Contributions}

Julia Velz - conception and design; acquisition of data; analysis and interpretation of data; and drafting the article. Marian Christoph Neidert, Kevin Akeret, Peter Nakaji, and Luca Regli - analysis and interpretation of data and critically revising the article. Yang Yang - acquisition of data and critically revising the article. Oliver Bozinov - conception and design; drafting the article; analysis and interpretation of data; and critically revising the article.

\section{Availability of Data and Material}

The datasets generated for this study are available on request to the corresponding author. 


\section{References}

1 Fritschi JA, Reulen H-J, Spetzler RF, Zabramski JM. Cavernous malformations of the brain stem. Acta Neurochir. 1994;130(1-4):35-46.

2 Kearns KN, Chen C-J, Tvrdik P, Park MS, Kalani MYS. Outcomes of surgery for brainstem cavernous malformations: a systematic review. Stroke. 2019;50(10):2964-6.

3 Garcia RM, Ivan ME, Lawton MT. Brainstem cavernous malformations: surgical results in 104 patients and a proposed grading system to predict neurological outcomes. Neurosurgery. 2015;76(3):265-8.

4 Nathal E, Patiño-Rodriguez HM, Arauz A, Imam SS, Acosta E, Evins AI, et al. Risk factors for unfavorable outcomes in surgically treated brainstem cavernous malformations. World Neurosurg. 2018;111:e478-84.

5 Porter RW, Detwiler PW, Spetzler RF, Bozinov O, Benes L, Sure U, et al. Cavernous malformations of the brainstem: experience with 100 patients. J Neurosurg. 1999;90(1): 50-8.

6 Abla AA, Lekovic GP, Turner JD, De Oliveira JG, Porter R, Spetzler RF. Advances in the treatment and outcome of brainstem cavernous malformation surgery: a single-center case series of 300 surgically treated patients. Neurosurgery. 2011;68(2):403-5.

7 Zaidi H, Mooney M, Levitt M, Dru A, Abla A, Spetzler R. Impact of timing of intervention among 397 consecutively treated brainstem cavernous malformations. Neurosurgery. 2017;81:620-6.

8 Dukatz T, Sarnthein J, Sitter H, Bozinov O, Benes L, Sure U, et al. Quality of life after brainstem cavernoma surgery in 71 patients. Neurosurgery. 2011;69(3):689-95

9 Gross BA, Batjer HH, Awad IA, Bendok BR, Du R. Brainstem cavernous malformations: 1390 surgical cases from the literature. World Neurosurg. 2013;80(1-2):89-93.

10 Zhang S, Lin S, Hui X, Li H, You C. Surgical treatment of cavernous malformations involving medulla oblongata. J Clin Neurosci. 2017;37:63-8.

11 Chotai S, Qi S, Xu S. Prediction of outcomes for brainstem cavernous malformation. Clin Neurol Neurosurg. 2013;115(10):2117-23.

12 Ferroli P, Sinisi M, Franzini A, Giombini S, Solero CL, Broggi G. Brainstem cavernomas: long-term results of microsurgical resection in 52 patients. Neurosurgery. 2005;56:12034.

13 Yang Y, van Niftrik B, Ma X, Velz J, Wang S, Regli L, et al. Analysis of safe entry zones into the brainstem. Neurosurg Rev. 2019;42(3): 721-9.
14 Yang Y, Velz J, Neidert MC, Bozinov O. Classification of brainstem lesion location. World Neurosurg. 2020;140:410-2.

15 Velz J, Vasella F, Yang Y, Neidert MC, Regli L, Bozinov O. Limited impact of serial followup imaging in clinically stable patients with brainstem cavernous malformations. Front Neurol. 2020 Aug;11(11):789.

16 Arauz A, Patiño-Rodriguez HM, ChavarriaMedina M, Becerril M, Longo GM, Nathal E. Rebleeding and outcome in patients with symptomatic brain stem cavernomas. Cerebrovasc Dis. 2017;43(5-6):283-9.

17 Li D, Wu Z-Y, Liu P-P, Ma JP, Huo XL, Wang $L$, et al. Natural history of brainstem cavernous malformations: prospective hemorrhage rate and adverse factors in a consecutive prospective cohort. J Neurosurg. 2020 Mar 13: $1-12$.

18 Li DA, Hao SYU, Jia GJ, Wu Z, Zhang LIW, Zhang JT. Hemorrhage risks and functional outcomes of untreated brainstem cavernous malformations: clinical article. J Neurosurg. 2014;121(1):32-41.

19 Menon G, Gopalakrishnan CV, Rao BRM, Nair S, Sudhir J, Sharma M. A single institution series of cavernomas of the brainstem. J Clin Neurosci. 2011;18(9):1210-4

20 Zimmermann RS, Spetzler RF, Lee KS, Zabramski JM, Hargraves RW. Cavernous malformations of the brain stem. J Neurosurg. 1991;75:32-9.

21 Moultrie F, Horne MA, Josephson CB, Hall JM, Counsell CE, Bhattacharya JJ, et al. Outcome after surgical or conservative management of cerebral cavernous malformations. Neurology. 2014;83(7):582-9.

22 Šteňo J, Bízik I, Šteňová J, Timárová G. Subtemporal transtentorial resection of cavernous malformations involving the pyramidal tract in the upper pons and mesencephalon. Acta Neurochir. 2011;153(10):1955-62.

23 Xie MG, Xiao XR, Guo FZ, Zhang JT, Wu Z, Zhang LW. Surgical management and functional outcomes of cavernous malformations involving the medulla oblongata. World Neurosurg. 2018;119:e643-52.

24 Zhang S, Li H, Liu W, Hui X, You C. Surgical treatment of hemorrhagic brainstem cavernous malformations. Neurol India. 2016;64: $1210-9$.

25 Wang CC, Liu A, Zhang JT, Sun B, Zhao YL. Surgical management of brain-stem cavernous malformations: report of 137 cases. Surg Neurol. 2003;59(6):444-54.
26 de Aguiar PHP, Zicarelli CAM, Isolan G, Antunes A, Aires R, Georgeto SM, et al. Brainstem cavernomas: a surgical challenge. Einstein. 2012;10(1):67-73

27 Bouillot P, Dufour H, Roche PH, Lena G, Graziani N, Grisoli F. [Angiographically occult vascular malformations of the brain stem. Apropos of 25 cases]. Neurochirurgie. 1996;42: 189-1.

28 Bricolo A, Turazzi S. Surgery for gliomas and other mass lesions of the brainstem. Adv Tech Stand Neurosurg [Internet]. 1995;22:261341.

29 Alves de Sousa A. Deep-seated (corpus callosum, intraventricular, basal ganglia and insula) and brain stem cavernous angiomas. Experience in Brazil TT: cavernomes profonds (corps calleux, intraventriculaires, ganglions de la base, insulaires) et du tronc cérébral. Neurochirurgie. 2007 Jun;53(2-3 Pt 2):18291.

30 Nataf F, Roux F-X, Devaux B, Page P, Turak B, Dezamis E, et al. Brainstem cavernomas: surgical experience at the $\mathrm{CH}$ Sainte-Anne general hospital TT - Cavernomes du tronc cérébral: l'expérience chirurgicale du centre hospitalier Sainte-Anne. Neurochirurgie. 2007 Jun;53(2-3 Pt 2):192-201.

31 Pandey P, Westbroek EM, Gooderham PA, Steinberg GK. Cavernous malformation of brainstem, thalamus, and basal ganglia: a series of 176 patients. Neurosurgery. 2013; 72(4):573-9.

32 Mathiesen T, Edner G, Kihlström L. Deep and brainstem cavernomas: a consecutive 8-year series. J Neurosurg. 2003;99(1):31-7.

33 Cantore G, Missori P, Santoro A. Cavernous angiomas of the brain stem. Intra-axial anatomical pitfalls and surgical strategies. Surg Neurol. 1999 Jul;52(1):84-4.

34 Lena G, Paz-Paredes A, Choux M. [Brain stem cavernomas in children. Nine case reports and literature review]. Neurochirurgie. 2002;48(4):319-25.

35 Taslimi S, Modabbernia A, Amin-Hanjani S, Barker F II, Macdonald R. Natural history of cavernous malformation: systematic review and meta-analysis of 25 studies. Neurology. 2016;86(8621):1984-91.

36 Abla AA, Lekovic GP, Garrett M, Wilson DA, Nakaji P, Bristol R, et al. Cavernous malformations of the brainstem presenting in childhood: surgical experience in 40 patients. Neurosurgery. 2010;67(6):1589-9.

37 Kalani MYS, Yagmurlu K, Martirosyan NL Cavalcanti DD, Spetzler RF. Approach selection for intrinsic brainstem pathologies. J Neurosurg. 2016;125:1596-607. 